\title{
Kar Amacı Olmayan İşletmelerde Entegre Raporlama ve Bir Örnek Olay
}

\author{
Anıl GACARa, b
}

Özet

Entregre raporlar, genellikle kar amacı olan işletmeler tarafından hazırlanmaktadır. Entegre raporlamanın kapsamının genişlemesiyle birlikte, literatürde kar amacı olan kuruluşların da entegre rapor hazırlayabilecekleri ve bunu toplumla paylaşabileceği belirtilmektedir. Ancak, entegre raporlama konusundaki literatür incelendiğinde, kar amacı olmayan işletmelerdeki entegre raporlama konusunda, oldukça aza sayıda çalışma olduğu görülmektedir. Çalışmada, kar amacı olmayan kuruluşlarda entegre raporlama ile ilgili kavramsal bigilere yer verilmekte ve bu bilgiler doğrultusunda Türkiye'deki bir işletme örnek olay kapsamında incelenmektedir. Bu amaç doğrultusunda, Türkiye' de eğitim alanında uzun yıllardır faaliyet gösteren ve 2018 yılında ilk entegre raporunu hazırlayıp sunan bir vakıf kuruluşu, örnek olay kapsamında ele alınmıştır. Örnek olay kapsamında incelenen kuruluşun ilgili faaliyet döneminde, mali olan ve olmayan bilgilerinin ayrıntılı bir biçimde hazırlanan entegre raporda yer aldığ görülmektedir.
Anahtar Kelimeler

Sosyal Muhasebe

Entegre Raporlama

Kar Amacı Olmayan İşletmeler

Makale Hakkında

Geliş Tarihi: 06.03.2020

Kabul Tarihi: 24.04.2020

Doi: $10.18026 /$ cbayarsos.699584

\section{Integrated Reporting in Nonprofit Businesses and A Case Study}

\begin{abstract}
Integated reports are usually prepared by for-profit businesses. The literature states that nonprofits can also prepare integrated reports and share it with the community with the expansion of the scope of integrated reporting. However, when the literature on integrated reporting is examined when the literature is examined. In this study, conceptual information about Integrated Reporting in non-profit organizations are included and in line with this information, a business in Turkey is examined within the context of a case study. For this purpose, a foundation organization that has been active in the field of education in Turkey for many years and has prepared and presented its first integrated report in 2018 has been taken into consideration within the context of a case study. It is observed that the financial and non-financial information of the organization examined within the context of the case study is included in the Integrated Report prepared in detail during the relevant activity period.
\end{abstract}

Keywords

Social Reporting

Integrated Reporting

Non Profit Businesses

About Article

Received: 06.03.2020

Accepted: 24.04.2020

Doi: $10.18026 /$ cbayarsos.699584

a İletişim Yazarı: anil.gacar@cbu.edu.tr

b Dr. Öğr. Üyesi, Manisa Celal Bayar Üniversitesi, İktisadi ve İdari Bilimler Fakültesi, İşletme Bölümü, ORCID: 0000-0002-4571-3886 


\section{Giriş}

Son dönemlerde rekabetin yoğunlaşmasının, işletmelerin sunduğu bilgilerden fayda sağlayabilecek paydaşların sayısında bir artış meydana getirdiği kabul edilebilir. Önceki yıllarda, işletmelerin en önemli paydaşı işletme sahip ve ortakları iken bu durum daha sonraki dönemlerde çalışanlar, devlet, tedarikçiler, çalışanlar, müşteriler ve sosyal sorumluluk ilişkileri boyutlarında genişlemiştir. Dolayısıyla, işletmeler açısından ortaklara yönelik raporlama ile birlikte diğer paydaşların da bilgi edinmesini sağlayan daha geniş bir raporlama gereksiniminin ortaya çıktığı kabul edilebilir.

Sürdürülebilirlik raporları ya da başka bir ifadeyle entegre raporlama, işletmeler tarafından açıklanması zorunlu (mali) bilgiler yanında mali olmayan bilgileri içeren bir sistem oalrak tanımlanabilir. Başka bir anlatımla, entegre raporlamada zorunlu olarak sunulması gerekli bilgiler ile birlikte işletmeler açısından sunulması zorunlu olmayan (gönüllü nitelikte açıklanabilen) bilgiler de yer almaktadır. Entegre raporlama aracılı̆̆ı ile artan paydaş sayısına bağlı olarak onların işletmeler hakkında bilgi edinme gereksinimi giderilmeye çalışılmaktadır.

Entegre raporlar, kar amacı olan işletmeler yanında kar amacı olmayan işletmeler için de hazırlanabilir. Argüden İletişim Akademisi, 2015 yılında Türkiye'de kar amacı olmayan bir işletme olarak ilk entegre raporu hazırlamıştır (Arıcı, 2018). Bu bağlamda, 2015 yılında ortaya konan bu çalışma ile Türkiye'de kar amacı olmayan işletmelerin de entegre rapor hazırlamaya başladıkları ve bu durumun ilglili alandaki diğer işletmeler üzerinde farkındalık oluşturabileceği kabul edilebilir.

\section{Sosyal Muhasebe ve Entegre Raporlama Kavramları}

Muhasebe bilgi sistemi, finansal tablo kullanıcılarının işletme yönetiminde karar almasına yardımcı olabilecek raporlarının hazırlanması ve finansal nitelikli işlemlerin kaydedilmesine ilişikin süreçler bütünü olarak ifade edilebilmektedir. Bu bakımdan, muhasebe, işletmelerin para ile ifade edilebilen işlemlerinin tanımlanması, sınıflandırılması, kaydedilmesi özetlenmesi ve raporlanması faaliyetleri olarak tanımlanmaktadır (Shim ve Siegel, 1999: 1). Muhasebe ile birlikte, işletmelerdeki tüm işletme fonksiyonlarından (pazarlama, üretim, finans, araştırma ve geliştirme vb.) gelen finansal nitelikli olaylar, finansal tablo kullanıcılarının bilgisine sunulmaktadır (Akgün ve Kılıç, 2013: 21). Buradaki amaç, işletmelerin mali yönü hakkında işletme sahipleri ve ortaklarına bilgi sağlamaktır.

İşletmelerde muhasebe bilgi kullanıcıları, iç ve dış kullanıcılar olmak üzere iki başlıkta incelenebilmektedir. İşletme içi kullanıcılar yöneticiler, ortaklar ve çalışanlar; dış kullanıcılar ise devlet, müşteriler, alıcılar, satıcılar, yatırımcılar vb. olarak sayılabilir (Toroslu ve Durmuş, 2017: 26). İç ve dış kullanıcıların bilgi ihtiyaçları birbirinden farklıdır. Dış kullanıcılar, yatırım yapma, borç verme ve mevzuata ilişkin kararlarla ilgilenirken iç kullanıcılar, planlama yapmak, kontrol etmek ve karar vermek amaciyla muhasebe bilgilerine gereksinim duyarlar (Jiambalvo, 2013: 7). Muhasebenin dış kullanıcılara yönelik olan kısmına finansal; iç kullanıcılara yönelik olan kısmına ise yönetim muhasebesi adı verilmektedir.

Yönetim muhasebesi, tarihsel süreç içerisinde ele alındığında farklı amaçlar üstlenmiştir. Buna göre yönetim muhasebesinin gelişimi dört farklı dönem itibariyle incelenebilmektedir (IMA, 1998: 84-85). Bu süreçler sırasıyla şu şekilde belirtilebilir: 
- 1950 öncesi dönem: Bu dönemde yönetim muhasebesinin amac1, maliyetlerin hesaplanması ve finansal kontroldür.

- 1950-1965 arası dönem: Maliyetlerin hesaplanması ve finansal kontrol ile birlikte, planlama da yönetim muhasebesinin amaçlarından biri olmuştur.

- 1965-1985 arası dönem: Bu dönemde, yenilikçi yönetim muhasebesi yaklaşımları (faaliyet tabanlı maliyetleme, kısıtlar teorisi vb.) kullanılarak işletme faaliyetlerinde maliyetlerin azaltılması amaçlanmaktadır.

- 1985 ve sonrası dönem: Bu dönemde, yönetim muhasebesinin temel amacinın müşteriler ve ortaklar için değer yaratmak olduğu söylenebilir. Bu bağlamda, işletmede finansal nitelikli olan ve olmayan tüm bilgiler değerlendirilerek işletmenin performansının ölçülmesi yoluna gidilmektedir.

Yönetim muhasebesindeki değişimin nedenleri arasında, yönetim muhasebesinin sosyal ve kültürel olaylardan da etkilenmesi gösterilebilir. Bu değişimin nedenleri olarak, işletme çevresinin büyüklüğü, üretim teknolojilerinin değişmesi, elektronik ticaretin yaygınlaşması, müşterilere odaklanma vb. gösterilebilir (Demir, 2008: 60). Muhasebede yaşanan dönüşüm ile birlikte daha fazla bilgi kullanıcısının gereksinimlerine yanıt verilmektedir. Yönetim muhasebesindeki dönüşüm ile birlikte sosyal muhasebe kavramı ortaya çıkmıştır. Sosyal muhasebe, işletmelerin yalnızca ortaklarına karşı değil; tüm paydaşlarına da sorumlu olduğu bir muhasebe alanı olarak değerlendirilmekte ve paydaşların işletme ile ilgili konularda karar vermelerine yardımcı olmalarını sağlayan bir alan olarak görülmektedir (Ertuna, 2012: 10). Kanada Yönetim Muhasecileri Topluluğu tarafından 1998 yılında hazırlanan yönetim muhasebesi rehberinde, işletme verimililiğinin arttırılmasının yolunun sosyal sorumluluk, çevresel ve sürdürülebilirlik uygulamalarından; dolayısıyla sosyal amaçlı muhasebeden geçtiği belirtilmektedir (Çelik, 2018).

Sosyal amaçlı muhasebe, işletmelerin sürdürülebilirlik faaliyetleri ile ilgili yapmış oldukları bilgilerin raporlanmasıdır. Sosyal muhasebe kavramı konusunda yapılmış bazı tanımlamalar bulunmaktadır. Camreon vd. (2010) sosyal muhasebeyi, işletmelerin amaç ve değerlerine ne ölçüde ulaştığını takip etme konusunda bir araç olarak tanımlamaktadır. Torrecchia (2013), sosyal muhasebenin, işletmelerin kurumsal sosyal sorumluluk ilkesi gereği olarak bütün faaliyetlerinin tanımlanması ve raporlanması süreci olduğunu ifade etmektedir. Doğan (2018), sosyal muhasebenin, işletmelerin sosyal sorumluluk ilkesinden yola çıkılarak ortaya çıkan bir muhasebe türü olduğunu belirterek; işletmelerin parasal olaylar dışında toplumu ilgilendiren ekonomik, yasal, etik vb. konularda da raporlama yapmak zorunda olduğunu belirtmektedir.

Sosyal muhasebenin bir başka tanımına göre sosyal muhasebe, işletmelerin sorumlu olduğu tüm gruplara karşı sahip olduğu yükümlülükler bütünüdir (Crowther, 2000). Mook vd. (2007)'ye göre sosyal muhasebe, toplumun bütün kesimlerine hesap veren bir sistemdir. Sozbilir (1981), sosyal muhasebeyi, kar amacı olan ya da olmayan herhangi bir işletmenin topluma olan ekonomik, sosyal vb. etkilerinin ölçülmesi ve bu etkilerin işletme içi ve dışındaki çıkar gruplarına raporlanması faaliyeti olarak tanımlamaktadır. Bütün bu tanımlar ele alındığında, sosyal muhasebenin kar amacı olan ya da olmayan işletmelerde, parasal işlemler dışında toplumu ilgilendirebilecek ekonomik, çevresel, sağlık vb. konularda toplumun bilgilendirmesi ve toplumla ilişkilerin geliştirilmesini amaçlayan bir kavram olduğu belirtilebilir. 
Gray (2002), sosyal muhasebenin farklı şekillerde adlandırılabileceğini belirtmektedir. Gray'e göre sosyal muhasebe, "sosyal sorumluluk muhasebesi, toplum denetimi, kurumsal sosyal raporlama, işçilere ya da işletme ortaklarına yönelik raporlama" şeklinde adlandırılabilmektedir. Juhman (2014), sosyal muhasebenin ortaya çıkma sürecinin, 1990'l1 yıllarda çok uluslu işletmeler tarafından başlatıldığını ifade etmektedir. Bu bağlamda, sosyal muhasebenin, işletmelerin büyümesi ya da yeni pazarlara ulaşması ile birlikte gelişim gösterdiği ifade edilebilir.

Hakcston ve Milne (1996), birçok işletmenin piyasa değerlerini daha da arttırmak düşüncesiyle sosyal muhasebeye önem verdiğini belirtmektedir. Thomson ve Zakaria (2004), sosyal muhasebenin işletme içi ve dışındaki bilgi kullanıcılarına işletmenin ekonomik, çevresel ve sosyal faaliyetlerinin raporlandığı bir sistem olduğunu belirtmektedir. Bir diğer tanıma göre sosyal muhasebe, işletmenin gerçekleştirdiği ya da gerçekleştirmeyi düşündüğü tüm faaliyetleriyle ilgili toplumu bilgilendirme çabasıdır (Sürmen ve Aygün, 2005). Bütün bu tanımlar ele alındığında, sosyal muhasebenin finansal muhasebedeki tek yönlü hissedar (ortak) odaklı anlayıştan toplumdaki diğer bilgi kullanıcılarına da yöneldiğini ifade etmek mümkündür.

Sosyal muhasebe sürecinin çıtıları, sosyal rapor olarak belirtilebilir. Sosyal raporlama, literatürde sürdürülebilirlik, entegre, kurumsal sürdürülebilirlik ve kurumsal vatandaşlık raporları gibi adlar almaktadır (Richards ve Wood, 2009). Wallage (2000), sosyal raporlama ile işletme ve çıkar grupları arasında iletişim ve karar alma süreçlerinde birlikte hareket edildiğini; bu bağlamda çıar gruplarının kendilerini ilgilendiren konularda bilgilenmesini amaçladığını belirtmektedir. Almanya, Hollanda, Fransa, Japonya vb. gelişmiş ülkelerde sosyal muhasebe ve dolayısiyla sosyal (entegre) raporlamaya 1970'li y1llardan bu yana oldukça önem verildiği belirtilmektedir (Batra, 1996).

Entegre raporlama, her türlü işletmenin sosyal faaliyetlerinin ilgili çıkar gruplarına ulaştırılmasını amaçlayan bir raporlama yaklaşımıdır (Kaya ve Karakaya, 2008). Entegre raporlama işletmelerin çevre, toplum, ekonomi ve diğer alanlara yaptığı katkılar hakkında kullanıcılara bilgiler sunmaktadır. Aynı zamanda, entegre raporlarda, işletmenin gelecekle ilgili hedef ve beklentilerine de yer verilebilmektedir. Entegre raporlama, muhasebenin temel kavramlarından olan sosyal sorumluluk ilkesinin gereği olarak düşünülmektedir (Idowu ve Towler, 2004).

\section{Entegre Raporlama ile İlgili Yazın Taraması}

Entegre raporlama ile ilgili olarak ulusal ve uluslararası alanda yapılmış birçok çalışma bulunmaktadır. Azim vd. (2009), Bangladeş'te yer alan işletmelerin entegre raporlarını inceleyen ampirik bir çalışma gerçekleştirmişlerdir. Analizde, incelenen 38 işletmeden 6 tanesinin kurumsal sosyal raporlama yaptığı ortaya çıkmış ve bu işletmelerin de ağırlıklı olarak bankacılık sektöründe olduğu ortaya konulmuştur. Lungu vd. (2011), Amsterdam, Paris, Lisbon ve Brüksel'deki işletmelerin 2007-2009 dönemleri arasındaki kriz döneminde entegre raporlamaya ne ölçüde önem verdiklerini ortaya koymayı amaçlayan bir çalışma gerçekleştirmişlerdir. Çalışmada ele alınan işletmelerin yıllık faaliyet raporları, içerik analizi ile değerlendirilmiştir. Çalışmada, Lisbon ve Brüksel'deki işletmelerin kriz dönemlerinde entegre raporlamaya daha az önem verdikleri belirtilmiştir. 
Maali vd. (2008), 16 ülkede bulunan toplam 29 İslami bankanın sosyal sorumluluk raporlarını incelemiştir. Çalışmada, İslami bankalar açısından sosyal sorumluluk raporlarının açıklanma oranının beklentilerin altında kaldığı belirtilmektedir.

Adams vd. (1998), 6 Avrupa ülkesinden 150 adet yıllık faaliyet raporunu analiz ettikleri çalışmalarında, entegre raporlamayı etkileyen etmenleri belirlemeye çalışmışlardır. Çalışma sonucunda, işletme büyüklüğü, işletmenin bulunduğu sektör ve ülkenin, işletmelerin sosyal sorumluluk açıklamalarını etkilediği ortaya konmuştur. Bununla birlikte, çok büyük işletmelerin, sosyal sorumluluk açıklamaları yapmalarının daha olası olduğu belirtilmiştir.

Tsang (1998), Singapur'da bankacılık, turizm ve gida sektöründen toplam 33 halka açık işletmenin, 1986-1995 yılları arasındaki yıllık faaliyet raporlarını incelemiştir. Çalışmada, 16 işletmenin incelenen on yıl boyunca, hiçbir sosyal sorumluluk açıklamasına sahip olmadığ belirlenmiştir. Geriye kalan 17 işletmenin faaliyet raporları cümle cümle analiz edilmiş ve bu işletmelerin ağırlıklı olarak insan kaynakları ve toplumsal katılımlar hakkında bilgi sunduğu ifade edilmiştir.

Ratanajongkol vd. (2006), 1997, 1998 ve 2001 dönemlerini kapsayacak şekilde, Tayvan'daki 40 büyük işletmenin yıllık faaliyet raporlarını sosyal sorumluluk açıklamaları açısından analiz etmişlerdir. Çalışmada, farklı endüstrilerde olmasına rağmen, Tayvan'da kurumsal sosyal sorumluluk açıklamalarının yıllar boyunca artış gösterdiği belirlenmiştir.

Adams ve Simnett (2011), entegre raporlama ile ilgili artan teşvik ve ivmelenme ile birlikte, Avustralya'daki kar amacı gütmeyen işletmeler için önemli fırsatlar olduğunu belirtmektedir.

Gazzola vd. (2017), İtalya' da kar amacı olmayan bir işletmenin entegre raporunu örnek olay yöntemi ile analiz etmiştir. Çalışmada, kar amacı olmayan işletmeler açısından sosyal sorumluluk uygulamalarının zorunlu olduğu ve bu tür işletmelerin kurumsal sosyal sorumluluklarını stratejilerine nasıl dahil edeceklerini ortaya koyan çalışmaların çok az sayıda olduğu belirtilmiştir.

Başar ve Başar (2006), o dönem İMKB (İstanbul Menkul Kıymetler Borsası) 100 Endeksinde yer alan işletmelerin entegre raporlarını niceliksel ve niteliksel göstergeler bakımından incelemişlerdir. 2003 yılının ilk üç aylık dönemine ilişkin faaliyet raporlarının incelendiği çalışmada, işletmelerin en çok insan kaynakları, sağlık ve güvenlik alanlarında; en az da enerji konularında açıklama yaptıkları belirlenmiştir.

Kaynar (2011), 2004-2009 yıllarını kapsayan süreçte İMKB 100 Endeksinde 4 çeyrekte de işlem gören işletmelerin kurumsal sosyal sorumluluk ile ilgili verilerini panel veri analiz yöntemini kullanarak değerlendirmiştir. Analiz sonucunda, işletmelerin kurumsal sosyal sorumluluk raporları ile finansal performansı arasında istatistiksel olarak anlamlı ve pozitif bir ilişki belirlenmiştir.

Kaya vd. (2016), 13 farklı ülkede yer alan işletmelerin yayınladıkları entegre raporlarını, kapsam ve içerik yönünden değerlendirmişlerdir. Çalışmada, entegre raporların finansal tablolarla aynı belge içinde sunulduğu ve kapsamının ülkeden ülkeye farklılık gösterebileceği belirtilmektedir. 
Ekergil ve Göde (2017), Küresel Raporlama Girişimi (Global Reporting Initative) Standartları'na göre seçilen otellerin sürdürülebilirlik raporlarını incelemişlerdir. Çalışmada, otellerin sürdürülebilirlik raporlarını uluslararası standartlara göre hazırlamadıkları belirlenmiştir.

Öztürk ve Marşap (2018), Amerika Birleşik Devletleri, İngiltere ve Türkiye'deki en büyük telekominikasyon işletmelerinin (Verizon, Vodafone ve Turkcell) kurumsal sosyal sorumluluk raporlarını incelemişlerdir. Çalışmada, İngiltere ve Türkiye'deki raporların "sürdürülebilirlik raporları"; Amerika'daki raporun ise "kurumsal sosyal sorumluluk raporu" ismi aldığı belirlenmiştir. Çalışmada ayrıca, işletmelerin ağırlıklı olarak çevresel ve toplumsal katılım faaliyetleriyle ilgili bilgiler sunduğu ortaya konmuştur.

\section{Kar Amacı Olmayan Kuruluşlarda Entegre Raporlama}

Sivil toplum kuruluşları, dernekler, vakıflar gibi kar amacı olmayan işletmelerin gerçekleştirdikleri sosyal sorumluluk faaliyetleri, toplumda farkındalık oluşmasını sağlamakta ve kurumların değerini arttırmaktadır (Çakır ve Arslan, 2016). Sosyal sorumluluk faaliyerlerinin yer aldığı raporlar, öncelikli olarak kar amacı olan işletmeler açısından ortaya çıkmış ve bu işletmelerin gönüllü uygulamalarına bırakılmıştır. Daha sonra, kar amacı olmayan sivil toplum kuruluşları, dernekler, vakıflar gibi kuruluşlar için de entegre raporların hazırlanabileceği belirtilmiştir (Çelebier ve Çankaya, 2019). Kar amacı olmayan işletmelerin de sürdürülebilirliği, yaptığı sosyo- ekonomik faaliyetlerin niteliğine değil; finsansal ve finansal olmayan bilgilerinin muhasebe bilgi kullanıcılarına sunulmasına bağlı olduğu belirtilmektedir (Uysal ve Kurt, 2016).

Uluslararası Entegre Raporlama Konseyi (International Inregrated Reporting Council-IIRC), uluslararası alanda entegre raporlarlamayla ilgili düzenlemeler ve standartlar yayınlayan bir kuruluştur. Kar amacı olmayan kuruluşlar, IIRC standartlarına uygun entegre rapor hazırlayabilmektedir (Yong ve Pozzoli, 2019). Bununla birlikte, kar amacı olmayan kuruluşların paydaşlarını; başka bir deyişle kendisinden yarar sağlayanları tanıması oldukça önemlidir. Bu kuruluşların paydaşları arasında, medya kuruluşları, üniversiteler, tedarikçiler, bağışçlar vb. birçok grup sayılabilir. Dolayısıyla, kar amacı olmayan kuruluşlar için şeffaflık ve iletişim oldukça önemlidir (Gazzola vd., 2017). Dumay vd. (2015), entegre raporlama ile ilgili yaptıkları literatür çalışmasında, kar amacı gütmeyen işletmelerle ilgili oldukça az sayıda çalışma yapıldığını ortaya koymaktadır. Dolayısıyla, kar amacı gütmeyen işletmeler açısından entegre raporlama konusunun hem ulusal hem de uluslararası düzeyde incelenmeye ve değerlendirilmeye açık bir alan olduğu kabul edilebilir.

\section{Araştırma Modeli}

Çalışmanın bu bölümünde, Türkiye'de 23 Ocak 1995 tarihinde kurulan Türkiye Eğitim Gönüllüleri Vakfı'na ait 2018 yılı entegre raporu, içerik analizi yöntemiyle analiz edilmektedir. Çalışmanın amacı, gelişmiş ülkelerde yaygın olarak kullanılan ve Türkiye'de henüz başlangıç aşamasında olan kar amacı olmayan kuruluşlarda entegre raporlama kavramını, bir örnek olay yardımıyla incelemektir. Bu amaçla, Türkiye'de geçmişi 25 yıla dayanan Türkiye Eğitim Gönüllüleri Vakfı örnek olay kapsamında seçilmiştir. Bu vakfın seçilmesinin nedeni, vakfın 26.12.2018-26.12.2019 tarihleri arasında 9,46 notu ile en yüksek kurumsal yönetim derecelendirme notuna sahip ikinci vakıf olmasıdır. Çalışma, Gazzola vd. (2017) tarafından yapılan çalışma temel alınarak hazırlanmıştır. 
Türkiye Eğitim Gönüllüleri Vakfı, devlet tarafından verilen temel eğitime destek amacıyla, birçok sanayici, yönetici ve akademisyen tarafından 23 Ocak 1995'te kurulmuş ve Türkiye'nin 33 şehir ve 73 farklı noktasında faaliyet gösteren bir sivil toplum kuruluşudur. Vakfın merkezi, İstanbul'dur. Vakıf, 2009'da Bakanlar Kurulu'nun aldığı karar ile izin almadan bağış toplama hakkına sahip bir vakıf olarak kabul edilmiştir (https://tr.wikipedia.org/, 27.02.2020). TEGV, devlet tarafından verilen eğitimin yanı sıra 6-14 yaş aralığındaki birçok çocuğun tiyatro, fen bilimleri, matematik gibi alanlarda gelişimine destek olmaktadır. TEGV, bu etkinliklerini birçok bağışçısının desteği ile karşılamakta; çocuklara verilen eğitimler de gönüllüler tarafından sağlanmaktadır (https://onedio.com/, 27.02.2020)

2018 yılı itibariyle TEGV'in rakamlarla genel görünümü şu şekildedir:

- Yaklaşık 191.000 ulaşılan çocuk

- Yaklaşık 25.000 bağ 1 ş̧̧ı

- Yaklaşık 9.000 aktif gönüllü

- Dijital platformlarda ulaşılan yaklaşık 260.000 çocuk

\section{Bulgular}

Türkiye Eğitim Gönüllüleri Vakfı'nın 2018 yılı faaliyetlerini ve geleceğe dönük stratejilerini bütünsel bir bakış açısıyla paylaşarak hazırlamış olduğu ilk entegre raporu olan bu rapor, 2018 yılına ilişkin öncelikli olarak değerlendirilen konu başlıkları doğrultusunda oluşturulmuştur. Hazırlanan entegre rapor ile, vakfın 2018 yılı faaliyetleri, gelecek planları, kaynakları, iş modeli ile yönetim yapısı ve bağımsız denetimden geçmiş finansal tabloları paydaşlarına sunulmaktadır.

TEGV 2018 yılına ilişkin entegre raporun sırasıyla şu başlıklardan oluştuğu görülmektedir (https://tegv.org, 27.02.2020):

- Sunuş

- Biz Kimiz?

- 2018 Yılı Faaliyetleri

- Kurumsal Yönetim

- Yanımızdakiler

- Raporlar

Entegre raporun sunuş bölümünde, vakfın entegre raporu hakkında bilgiler ile yönetim kurulu başkanı ve genel müdürün mesajı yer almaktadır. Bı bölümde vakfın temel amacının “Birleşmiş Milletler (BM) 2030 Sürdürülebilir Kalkınma Hedeflerine Katkı" olduğu belirtilmektedir.

İkinci bölümde, TEGV misyonu, vizyonu ve değerleri; vakfın dış paydaşları, stratejik hedefleri, vakfı bekleyen riskler ve fırsatlar ile yaratılan değerler hakkında bilgilere yer verilmektedir. Raporda, vakfın iş modelinin çocuklar, gönüllüler, eğitim programları, mekanlar, izleme değerlendirme ve yönetişim olmak üzere 6 ana boyuttan oluşuğu belirtilmiştir. Kurumun stratejik hedefleri ise ulaşılan çocuk sayısını arttırmak, bilgi 
teknolojilerinde ilerlemek, bağışçıların bağlılığını arttırmak ve mali yapıda bağlılık olarak belirlenmiştir.

Raporun üçüncü bölümünde, vakfın 2018 yılı sonu itibariyle genel görünümüne ilişkin bilgiler yer almaktadır. Bu bölümde, 2018 yılı içerisinde yapılan faaliyetler, vakfın gönüllüleri, dijitalleşme konusunda yapılan girişimler ve vakfın işbirlikleri ile ilgili bilgiler yer almaktadir.

Raporun dördüncü ve beşinci bölümünde, vakfın kurumsal yönetim konusunda yaptığ çalışmalar ve yapılan faaliyetler ile ilgili diğer kuruluşlardan alınan destekler hakkında bilgiler yer almaktadır. Vakfın kurumsal yönetim kapsamında, icra, denetim, kurumsal yönetişim, etik, risk yönetimi ve eğitim danışma komiteleri olmak üzere 6 farklı komiteden oluştuğu gözlenmiştir. Raporda ayrıca, her bir komitenin görev ve sorumlulukları hakkında bilgiler yer almaktadır. 2018 yılı sonu itibariyle, vakfın bireysel ve kurumsal bağışçılardan toplam 21.819.513 TL bağış topladığı belirtilmektedir.

Raporlar başlığı altında, vakfa ait kurumsal yönetim ilkelerine uyum beyanı, vakfın 2018 yılı hesap dönemine ilişkin bilanço ve gelir tablosu ile bunlara ilişkin bağımsız denetçi raporu yer almaktadır. Finansal tablolara ilişkin yapılan bağımsız denetim sonucunda, vakfın finansal tablolarının tekdüzen hesap planına ve gerçeğe uygun olarak hazırlandığ belirtilmiştir. Bununla birlikte, vakfın 2018 yılında elde ettiği gelirlerin 2017 yılına göre yaklaşık 2.500.000 TL; buna karşılık giderlerinin de bir önceki yıla göre yaklaşık 6.000.000 TL arttığı görülmüştür. Dolayısıyla vakfın finansal bakımdan gelirlerinin giderlerine oranla daha az arttığ $\breve{b}$ belirtilebilir.

TEGV tarafından 01.01.2018-31.12.2018 dönemini kapsayacak şekilde hazırlanan entegre rapor ile vakıf faaliyetleri hakkında paydaşlara şeffaf, hesap verebilir ve tutarlı bilgiler sunulduğu kabul edilebilir. TEGV'in, Türkiye'de en yüksek kurumsal yönetim notuna sahip vakıflarından biri olması, entegre rapor hazırlanmasında önemli bir rol olarak değerlendirilebilir. Bununla birlikte, çeşitli alanlarda faaliyet gösteren kar amacı olmayan işletmelerin, toplumla ilişkilerinin artırılması amacıyla entegre raporlamaya önem vermeleri gerektiği ve bu raporlarını da kamuoyuyla paylaşmaları gerektiği ifade edilebilir.

\section{Tartışma, Sonuç ve Öneriler}

Son dönemlerde muhasebeyle ilgili çıkar grupları, işletmelerle ilgili finansal bilginin yanında finansal olmayan bilgiler hakkında da bilgi sahibi olmak istemektedir. Finansal olmayan bilgiler, işletmelerin sosyal sorumluluk ilkesi gereği yaptığı faaliyetler ile ilgilidir. İşletmelerin sosyal sorumluluk faaliyetleri hakkında gönüllü olarak bilgi vermesi, işletmelerin toplumda bilinirliğini ve dolayısıyla piyasa değerini arttırıcı bir unsur olarak değerlendirilmektedir.

Entegre raporlama, hem kar amacı olan hem de olmayan işletmeler açısından hazırlanabilmektedir. Amerika ve Avrupa'daki ülkelerde kar amacı olmayan işletmelerin entegre rapor hazırlamaları daha eski yıllara dayanırken; bu durumun Türkiye açısından oldukça yeni olduğu ifade edilebilir. Çalışmada, kar amacı olmayan işletmelerden biri olan Türkiye Eğitim Vakfı özelinde hazırlanan ilk entegre rapor, örnek olay kapsamında incelenmiştir. Türkiye Eğitim Vakfı'nın 2018 yılına ilişkin entegre raporunun incelendiği çalışmada, vakfın bir yıl boyunca gerçekleştirdiği sosyal sorumluluk faaliyetleri ile finansal olan ve olmayan tüm bir arada sunulduğu görülmüştür. 
Türkiye'de daha önce yapılmış çalışmalarda, kar amacı olmayan işletmelerde entegre raporlamanın örnek olay kapsamında incelenmesi konusu ile ilgili olarak herhangi bir çalışmaya rastlanmamıştır. Çalışmanın, bu anlamda daha sonra yapılacak çalışmalar açısından başlangıç niteliği taşıdığı belirtilebilir. Bununla birlikte, entegre raporlamanın kar amacı olmayan işletmeler açısından bilinirliğinin artması beklenmektedir. Daha sonraki aşamalarda, farklı ülkelerde birden fazla kar amacı olmayan işletmenin entegre raporları karşılaştırmalı olarak ele alınarak aralarındaki Türkiye açısından benzerlik ve farklılıklara ilişkin çalışmalar gerçekleştirilebilir.

\section{Kaynakça}

Adams, C. vd. (1998). Corporate Social Reporting Practices in Western Europe: Legitimating Corporate Behaviour?, The Brtisih Accounting Review, 30(1), 1-21

Adams, S. ve Simnett, R. (2011). Integrated Reporting: An Opportunity for Australia's Notfor-Profit Sector. Australian Accounting Review, 21(3), 292-301

Akgün, A.İ. ve Kılıç, S. (2013). Muhasebe Bilgi Sisteminin İşletme Yönetiminin Etkinliği Üzerindeki Etkisi. Yönetim ve Ekonomi Dergisi, 20(2), 21-36

Arıcı, N. D. (2018). Entegre Raporlama Yolculuğunda Sürdürülebilirlik Raporlamasının Rolü: OECD ve Türkiye Karşılaştırması. Mali Çözüm Dergisi, Eylül-Ekim, 61-83

Azim, M. vd. (2009)'Corporate Social Reporting Practice: Evidence from Listed Companies in Bangladesh', Journal of Asia-Pacific Business, 10:2, 130-145

Başar, B. ve Başar, M. (2006). Sosyal Sorumluluk Raporlaması ve Türkiye'deki Durumu. Sosyal Bilimler Dergisi, 2, 213-230

Batra, G.S.(1996) “Dynamics Of Social Auditing in Corporate Enterprises: A Study Of The Indian Corporate Sector", Managerial Auditing Journal, Volume: 11 Issue: 2, 36 - 45

Cameron vd. (2010). Social Accounting: A Practical Guide for Small Community Organisations and Enterprises. Centre for Urban and Regional Studies, The University of Newcastle, Australia.

Crowther, David (2000)., Social and Environmental Accounting, London: Financial Times Prentice Hall

Çakır, A. ve Arslan, B. (2016). Kurumların Uyguladıkları Sosyal Sorumluluk Projelerinin Tüketicilerin Marka Sadakati Üzerine Etkileri: Otomobil Markaları Üzerine Bir Araştırma. СВÜ Sosyal Bilimler Dergisi. 14(2), 437-452

Çelebier, M. ve Çankaya, F. (2019). Entegre Raporlama ile ilgili Yapılan Çalışmalar: Literatür Çalışması. Uluslararası Ekonomi ve Yenilik Dergisi. 5(2). 179-196

Çelik, Y. (2018). Sürdürülebilirlik Muhasebesi, Sürdürülebilirlik Raporlama İlkeleri (GRI), BIST Sürdürülebilirlik Endeksinde İşlem Gören Bankaların Sürdürülebilirlik Raporlarmın Karşılaştırılması. Başkent Üniversitesi Sosyal Bilimler Enstitüsü Yayımlanmamış Yüksek Lisans Tezi.

Demir, Volkan (2008). Yönetim Muhasebesindeki Değişim ve Değişimi Etkileyen Faktörler, Muhasebe ve Denetime Bakış Dergisi, Yıl: 8, Sayı: 26, Ekim - 2008, 51 - 70. 
Doğan, S. (2018). Kurumsal Sosyal Sorumluluk Ve Muhasebenin Sosyal Sorumluluğu. Balkan ve Yakın Doğu Sosyal Bilimler Dergisi. 4(1). 100-107

Dumay, J. vd. (2016). Integrated reporting: A structured literature review. Accounting Forum, 40(3), 166-185

Ekergil, V. ve Göde, M. Ö. (2017). Küresel Raporlama Girişimi (GRI) Standartlarına Göre Seçilen Otellerin Sürdürülebilirlik Raporlarının Analizi ve Değerlendirilmesi. Business and Economics Research Journal. 8(4), 859-871

Ertuna, Ö. (2012). Muhasebe İçin Yeni Ufuklar: Sosyal Muhasebe, Muhasebe ve Finans Tarihi Araştırmaları Dergisi (MUFITAD), 3, 5-18.

Gazzola, P. vd. (2017). CSR and Sustainability Report for Nonprofit Organizations. An Italian Best Practice. Management Dynamics in the Knowledge Economy. 5(3), 355-376

Gray, R. (2002). The social accounting project and Accounting Organizations and Society Privileging Engagement, Imaginings, New Accountings and Pragmatism over Critique?, Accounting, Organizations and Society 27, 687-708

Hackston, D., Milne, M. (1996). Some Determinants of Social and Environmental Disclosures in New Zealand Companies. Accounting, Auditing \& Accountability Journal. 9(1), 77- 94.

Idowu, S. O. ve Towler, B. A. (2004), A Comparative Study of the Contents of Corporate Social Responsibility Reports of UK Companies. Management of Environmental Quality: An International Journal, 15(4), 420-437.

IMA (International Management Accountant). International Management Accountant Statements-1, Management Accounting Principles

Jiambalvo, J. (2013). Managerial Accounting. Fifth Edition, Wiley Sons.

Kaya, U. ve Karakaya, A. (2008). Sosyal Raporlama Anlayışının Muhasebe Meslek Mensupları Tarafından Algılanması Üzerine Ampirik Bir Çalışma. Muhasebe ve Denetime Bakış, 7( 24), 153-170.

Kaya, U. vd. (2016). Yeni Bir Kurumsal Raporlama Yaklaşımı Olarak Entegre Raporlama ve Dünyadaki Uygulama Örnekleri Üzerine Bir Araştırma. Karadeniz Teknik Üniversitesi Sosyal Bilimler Enstitüsü Sosyal Bilimler Dergisi. 6(11), 85-101

Kaynar, B. (2011). Kurumsal Sosyal Sorumluluk Anlayışına Dayalı Sosyal Raporlamanın İşletme Performansı Üzerine Etkisi: Türkiye Uygulaması. Afyon Kocatepe Üniversitesi Sosyal Bilimler Enstitüsü, Yayımlanmamış Doktora Tezi

Kılıç, B. (2018). Entegre Raporlama ve Türkiye'deki Gelişmeler: Entegre Rapor Hazırlayan İşletmeler ve BİST Kurumsal Sürdürülebilirlik Endeksinde Yer Alan İşletmeler Açısından Bir İnceleme. Muhasebe Bilim Dünyası Dergisi. 20(1). 28-64

Lungu, C.I vd. (2011), Exploratory Study on Social and Environmental Reporting of European Companies in Crises Period. Accounting and Management Information Systems. 10(4), 459-478

Maali, B. vd. (2008), Social Reporting by Islamic Banks. A Journal of Acounting, Finance and Business Studies.42(2), 266-289 
Öztürk,C. ve Marşap, B. (2018). Corporate Social Responsibility Reporting in Telecommunication Industry: The Case of the US, UK, and Turkey. Muhasebe ve Finansman Dergisi. Nisan, 217-234

Ratanajongkol, S., Davey, H. and Low, M. (2006), Corporate social reporting in Thailand: The news is all good and increasing, Qualitative Research in Accounting \& Management, 3 (1), 6783. https://doi.org/10.1108/11766090610659751

Richards, B. ve Wood, D. (2009). The Value of Social Reporting Lessons Learned From a Series of Case Studies Documenting The Evolution of Social Reporting at Seven Companies. Boston College Center for Corporate Citizenship

Shim, J. K. and Siegel, J. G. (1999). Theory And Problems of Financial Accounting (2.b.). New York: McGraw-Hill Companies, Inc.

Sozbilir, H. (1981). İşletmelerde Sosyal Muhasebe Kuramı ve Türkiye'de Bir Anket Çalışması. Neriman ve İbrahim Küçükkurt Sosyal Hizmetler, Eğitim, Sağlık ve Bilimsel Araştırma Vakfı Yayınları, No:1

Sürmen, Y. ve Aygün, D. (2005). İşletmelerde Sosyal Raporlama, Muhasebe Finansman Dergisi, $26,35-42$

Thompson, P., Zakaria, Z. (2004). Corporate Social Responsibility Reporting in Malaysia. The Journal of Corporate Citizenship, Spring, 13, 125- 136.

Toroslu, V. ve Durmuş, C. N. (2017). Finansal Tablolar Analizi: Kavramlar ve Analiz Teknikleri, Seçkin Yayıncılık

Torrecchia P. (2013) Social Accounting. In: Idowu S.O., Capaldi N., Zu L., Gupta A.D. (eds) Encyclopedia of Corporate Social Responsibility. Springer, Berlin, Heidelberg

Tsang, E. W.K. (1998). A Longitudinal Study of Corporate Social Reporting in Singapore: The Case of the Banking, Food and Beverages and Hotel Industries, Accounting, Auditing $\mathcal{E}$ Accountability Journal, 11(5), 624-635

Uysal, T. ve Kurt, G.U. (2016). Kar Amaci Gütmeyen İşletmelerde Denetim: Bir Paradoks Mu? Süleyman Demirel Üniversitesi İktisadi ve İdari Bilimler Fakültesi Dergisi. Muhasebe Denetimi Özel Sayısı. 21(5), 1555-1559

Wallage, P. (2000). Assurance on Sustainability Reporting: An Auditor View. Auditing, 19: 5365.

Yong, J. ve Pozzoli, M. (2019). Benefits of Integrated Reporting for Small Businesses and Not for Profit Organizations. https://www.ifac.org/knowledge-gateway/contributing-globaleconomy/discussion/benefits-integrated-reporting-small (25.02.2020)

https://onedio.com/ (27.02.2020)

https://tegv.org.tr/ (27.02.2020)

https://tr.wikipedia.org/ (27.02.2020) 